\title{
Analysis of Bolted Flanged Panel Joint for GRP Sectional Tanks
}

\author{
S. M. Radhakrishnan • B. Dyer • M. Kashtalyan • \\ A. R. Akisanya $\cdot$ I. Guz • C. Wilkinson
}

Received: 17 October 2013 / Accepted: 9 January 2014 / Published online: 1 February 2014

(C) The Author(s) 2014. This article is published with open access at Springerlink.com

\begin{abstract}
The performance of flanged panel bolted joints used in Glass Reinforced Plastic (GRP) sectional tanks is investigated using a combination of experimental and computational methods. A four-panel bolted assembly is subjected to varying pressure in a rupture test rig to study damage development at the intersection of the four panels. It is found that cracking initiates at a panel corner at the four panel intersection at a pressure of $35 \mathrm{kPa}$ and propagates to other panel corners with increasing pressure. This is attributed to the excessive deformation at the four panel intersection. The effect of bolt spacing, varying end distances and bolt pre-tension in decreasing the localized deformation and maximum induced stresses are investigated using finite element analysis. It is found that varying the amount of bolt spacing and end distances had a considerable influence on the joint performance whereas varying bolt pretension had very negligible effect. Consequently, this study establishes the maximum pressure which the GRP panel joint can withstand without failure and the corresponding optimum joint parameters.
\end{abstract}

Keywords Bolted flanged panel joints $\cdot$ Sheet moulding compounds $\cdot$ Joint parameters $\cdot$ Experimental testing $\cdot$ Finite element modelling

\section{Introduction}

Sectional bolted tanks are increasingly being used to replace conventional concrete water storage tanks due to their ease of assembly, production, transportation and maintenance. Made from a series of panels bolted together on site, they offer almost an infinite range of sizes and capabilities and are particularly functional in confined spaces. Low alloy steel has been widely used in sectional tank design due to its strength and durability. However it is very susceptible to corrosion when used in high temperature and high humidity environments [1]. Glass Reinforced Plastic (GRP) is seen as an attractive alternative material to low alloy steel, mainly

S. M. Radhakrishnan • B. Dyer • M. Kashtalyan $(\bowtie) \cdot$ A. R. Akisanya $\cdot$ I. Guz School of Engineering, College of Physical Sciences, University of Aberdeen, Aberdeen AB24 3UE, UK e-mail: m.kashtalyan@abdn.ac.uk

S. M. Radhakrishnan • C. Wilkinson

Balmoral Tanks Ltd., Llantrisant Business Park, Llantrisant, Pontyclun, CF72 8LF Wales, UK 
due to is high corrosion resistance in extreme climatic conditions. Compared to steel, GRP also offers reduced maintenance costs and ease of handling due to its low weight, high strength-toweight ratio, good resistance to bacterial growth, reduced risk of osmotic attack and production cycle time [1].

GRP sectional tanks are typically made of panels with symmetrical geometries to allow for simple and fast installation. Tank panels are produced using hot press compression moulding of sheet moulding compounds (SMC) and have flanges which are bolted together with an elastomeric sealant sandwiched between the flanges to prevent leakage. These compounds consist of a mixture of unsaturated polyester, glass fibre and fillers. They have good mechanical properties, dimensional accuracy, smooth surface finish and durability. Polyester moulding compounds are generally brittle and failure in the panels can be classified into two categories: Total failure and matrix cracking failure. Total failure is said to occur when the panels attain maximum load before catastrophic failure whereas matrix cracking failure is said to occur when the panels attain a load which initiates cracking in the composite matrix [2]. In case of tank panels where leak tightness is a crucial factor, panels are said to fail when matrix cracking occurs as this can lead to a leak path.

Previous studies on mechanically fastened GRP joints have shown that stress distribution is largely uneven with unequal stress peaks along the joint. This is mainly attributed to the absence of load sharing due to plastic yielding [3, 4]. Baillie et al. [5] suggested that all bolts in a given joint are only loaded equally at failure, while Madenci et al. [6] showed that the maximum bolt hole stress occurred closest to the loaded edge. The commonly observed modes of failure in bolted composite joints are similar to the ones observed in metallic bolted joints namely: tension, cleavage, bearing and shear out. Net-tension and shear out failure are catastrophic whereas bearing failure is associated with compression damage accumulation which depends strongly on the contact and frictional forces at the bolt hole. The ideal mode of failure is bearing wherein the damage is progressive and not catastrophic [7, 8]. Bearing failure is associated with the compressive properties of the composites [9]. In composite bolted joints, cleavage failure generally occurs when a joint is subjected to bending and the end and side distances of the bolts are very small. Hart-Smith [8] suggests that shear out failure is closely related to bearing occurring at small end distances. Sometimes, more than one failure mode occurs together. In the case of multi-bolted joints, a tensile failure may occur between adjacent bolts followed by a bulk shear out of the material between the bolts and the free edge [3]. Failure modes in metal bolted joints are highly dependent on the width of the plate and the end distance of the bolt similar to composite bolted joints. Lap-shear tests of cold-formed steel bolted joints showed that bearing failure occurred when the strip width and end distance was very large. Shear out failure occurred at smaller end distances of the bolt whereas net-section failure occurred at low strip widths [10-14].

Joint parameters like arrangement and number of bolt holes, laminate thickness, distance from laminate edge to the bolt hole and bolt hole diameter govern the failure mode under a particular type of loading [4, 15-18]. Tensile test results of GRP joints by Godwin et al. [3] showed that catastrophic tensile failure occurred when the edge distance to bolt hole diameter ratio was less than 5 , while bearing failure was observed when the ratio was greater than 5 . Furthermore, catastrophic tensile failure also occurred when the bolt pitch to diameter ratio equal to or less than 2.5, whereas full bearing strength was achieved when the pitch was more than six times the diameter. At small values of pitch in a wide panel an increase in strength may be gained by increasing end distance to suppress shear-out failure [3].

The effect of the number of bolts in GRP bolted joints in increasing joint efficiency was studied by Hart-Smith [8] who suggested that while two bolts may increase joint strength by $10 \%$ as many as eight or ten will be needed to give a $25 \%$ increase indicating diminishing 
returns with increased joint complexity. Studies conducted by Stoekdale and Matthews [19] in the past to see the effect of bolt clamping load in increasing the joint efficiency have shown that fully tight bolts led to slight increase in failure load but this was observed only in cases where the pitch to diameter ratio are high. It was found that a combination of delamination and compressive failure occurred when no washers were used and the bolt was just finger tight. The presence of washers and a certain amount of clamping load increased the performance of bolted joints and changed the failure mode to compressive failure at the bolt holes [20]. However, there was an optimum level of clamping load above which a compressive damage occurred at the washer-laminate interface [19].

Experiments have also been conducted in the past to investigate the mechanical behaviour of bolted Sheet Molding Compound (SMC) joints. The major drawback of using compression moulded SMC is that it is brittle under flexural loading due to its high filler content which is further aggravated by introducing local stress concentration due to geometric non-linearity in the form of sharp corners and bolt holes. Experiments have been carried out using different thicknesses of SMC laminates bolted to relatively rigid support systems and subjected to compression, flexure and shear loading [2]. When the ratio of the SMC thickness to the bolt hole diameter ratio was greater than 3 , the failure load was the same for all three modes of loading. However, for smaller thickness to bolt hole diameter ratio, the failure load was highest in compression and least in flexure. In compression loading, matrix micro cracking was the major failure mode whereas in flexure large cracks propagated leading to fibre fracture and catastrophic failure. The performance of bolted joints is highly dependent on the rigidity of the support. If a rigid support induces flexure then the onset of cracking and ultimate failure is decreased by an order of magnitude [21]. It is clear from the above that the analysis and design of bolted joints involves complex interaction between material properties, bolt size and installation method and configuration. Although analysis and experiments have been performed in the past to investigate the failure behaviour of SMC bolted joints under different modes of loading and of GRP flanged joints in pipes [22-25], there are no studies in open literature on the effect of various joint parameters on the structural integrity of SMC flanged panel bolted joints under hydrostatic pressure. This is particularly relevant to the assessment of the performance of sectional tanks where the bolted joints are subject to hydrostatic pressure resulting from the content of the tank.

In this study, we examine the damage evolution in SMC bolted panels in sectional tanks subjected to varying hydrostatic pressure using rupture testing. The effects of bolt spacing and bolt pre-tension on the structural integrity of the joints are investigated using Finite Element Analysis (FEA).

\section{Experimental}

\subsection{Materials}

SMC panels made from an isophthalic unsaturated polyester resin and E-glass fibre reinforcement are used in this study $[26,27]$. The panels were manufactured by Balmoral Tank Ltd. ${ }^{1}$ using a hot-press moulding process. The process results in strong, consistent panels which are fully cured, dimensionally accurate with sharply defined profiles and smooth surfaces.

Four $500 \mathrm{~mm} \times 500 \mathrm{~mm} \times 9 \mathrm{~mm}$ panels were bolted together along the flange of width $79 \mathrm{~mm}$ and thickness of $12 \mathrm{~mm}$. The assembly was subjected to varying uniform pressure on

\footnotetext{
${ }^{1}$ Balmoral Tanks Ltd., Llantrisant Business Park, Llantrisant, Pontyclun, CF72 8LF, Wales, UK
} 
Fig. 1 Rupture testing rig with mounted deflection meter

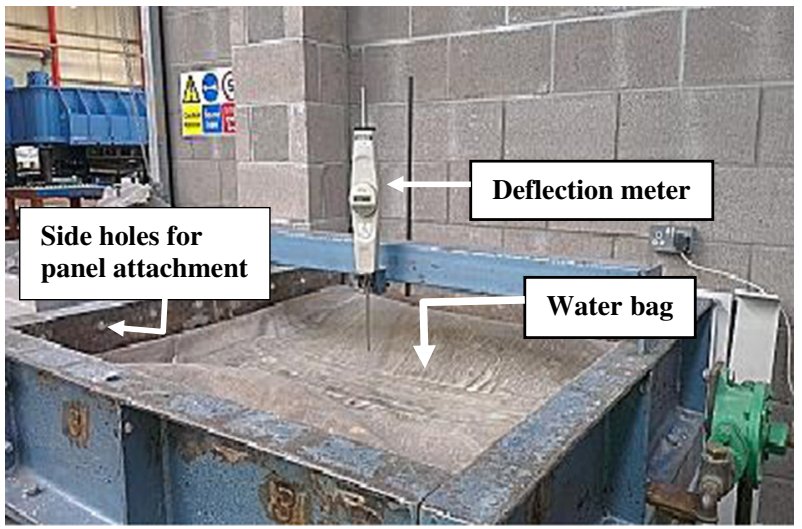

one of the surfaces in a specially designed rupture test rig [28] and the damage initiation and propagation in the panels were examined. The deflection at the cruciform area was also recorded at different pressures.

\subsection{Experimental Set-Up and Method for Rupture Test}

A rigid support system was constructed from C-beam in the shape of a cuboid. Holes were drilled along the top edges of the cuboid to allow for the attachment of the panels. A polyethylene water bag, which was connected via a high pressure hose to a hand pump, was placed on a rigid base inside the cuboid (see Fig. 1). The four panel bolted assembly was bolted to the sides of the support system. The bolt hole diameter in the panel flanges was $13.5 \mathrm{~mm}$ and the end distance of the outermost bolt hole to the edge of the panel was $62.5 \mathrm{~mm}$. The bolt hole spacing was $125 \mathrm{~mm}$. The bolts which are $12 \mathrm{~mm}$ in diameter were tightened using a torque value of $43 \mathrm{~N} . \mathrm{m}$ which gives an approximate clamping load of $2.08 \mathrm{kN}$. The bolt preload was calculated using the following equation [29]

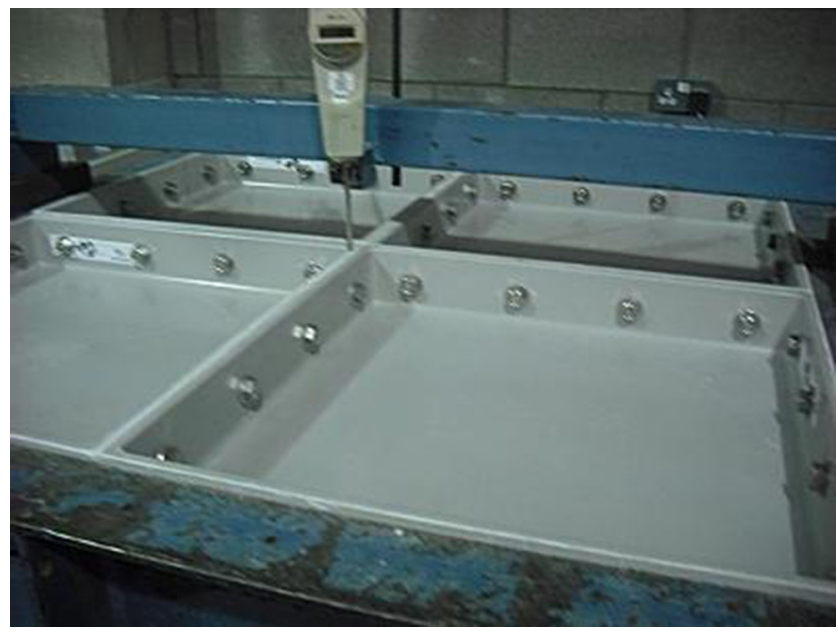

Fig. 2 Four panel bolted assembly bolted on to the rupture testing rig. The deflection meter is placed at the cruciform area 
Table 1 Pressure-deflection data at the cruciform area with failure events occurring at each pressure

\begin{tabular}{|c|c|c|}
\hline $\begin{array}{l}\text { Pressure } \\
(\mathrm{kPa})\end{array}$ & $\begin{array}{l}\text { Deflection at the } \\
\text { cruciform area } \\
(\mathrm{mm})\end{array}$ & Comments \\
\hline 10 & 1.78 & No cracking \\
\hline 15 & 3.19 & No cracking \\
\hline 20 & 4.54 & No cracking \\
\hline 25 & 6.01 & No cracking \\
\hline 30 & 7.50 & No cracking \\
\hline 35 & 9.30 & $\begin{array}{l}\text { A single corner cracked at the } \\
\text { intersection of the four panels }\end{array}$ \\
\hline 40 & 11.60 & $\begin{array}{l}\text { Crack propagation to the other corners } \\
\text { (end of fillet radius - refer Fig. } 3 \mathrm{~b} \text { ) } \\
\text { at the intersection of the four panel }\end{array}$ \\
\hline 50 & 14.34 & Crack propagation along the panel corners \\
\hline
\end{tabular}

$$
F=\frac{T}{K d}
$$

where $F$ is the bolt preload (N), $T$ is the torque value (N.m), $K$ is the torque factor $(0.2$ on average) and $d$ is the nominal bolt diameter (m). Since the bolts used are unplated, $90 \%$ of torque is used to overcome friction between the head of the bolt and composite panel and also between the threads of the bolt and the nut. Only $10 \%$ of the applied torque provides the clamp load [30]. Assuming, approximately 5 N.m is converted to clamp load gives a bolt preload of $2.08 \mathrm{kN}$. The deflection at the intersection of all the four panels (thereafter referred to as the cruciform area) was measured using a deflection meter. The entire test set-up is shown in Fig. 2.

The water bag was filled at a very slow rate i.e. in increments of $5 \mathrm{kPa}$ at $4 \mathrm{~s}$ intervals in order to achieve a quasi-static loading state. Recall that the water bag was placed on a rigid base in the support system. So as the water bag was filled, it expanded upwards applying a uniformly distributed pressure on the whole underside of the clamped SMC panels. The loading was continued until rupture. Deflection was recorded at $5 \mathrm{kPa}$ intervals up to $40 \mathrm{kPa}$, then at $10 \mathrm{kPa}$ intervals until rupture.

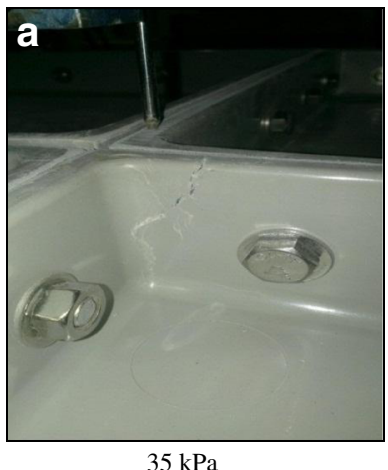

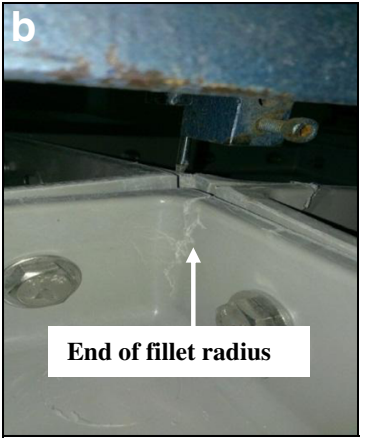

$40 \mathrm{kPa}$

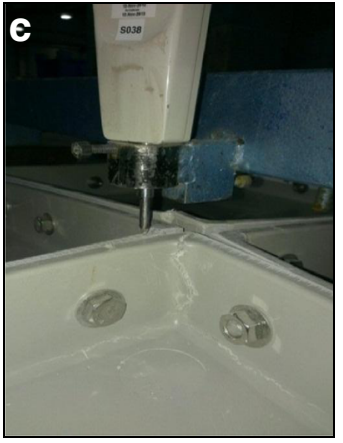

$50 \mathrm{kPa}$

Fig. 3 Crack initiation and propagation pattern at the cruciform area a $35 \mathrm{kPa}, \mathbf{b} 40 \mathrm{kPa}$, c $50 \mathrm{kPa}$ 
Fig. 4 Dog-bone shaped bolt

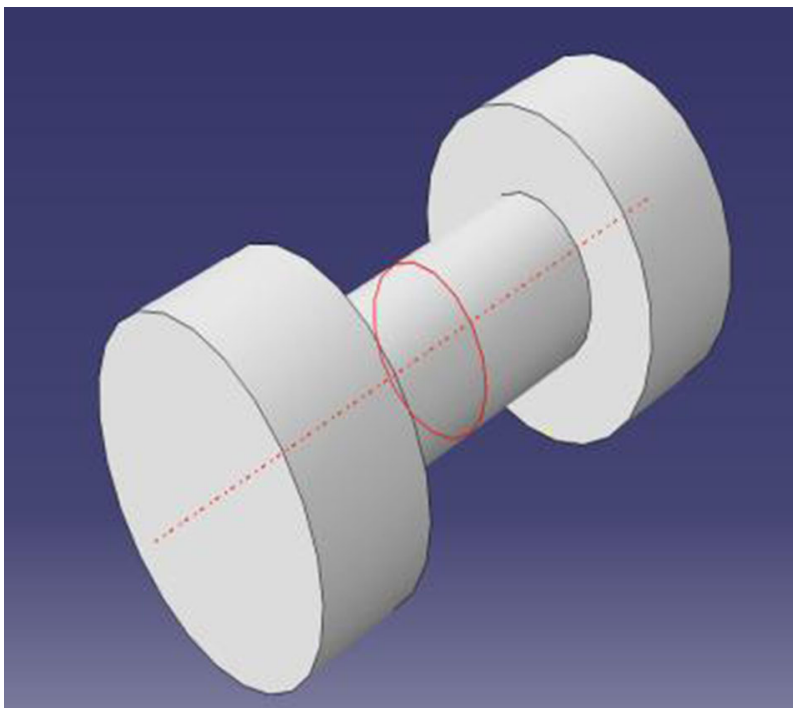

\subsection{Experimental Results}

As expected the deformation of the panel increases with increasing applied pressure with maximum deflection occurring at the intersection of the four panels, i.e. at the centre of the assembly. The maximum deflection and the respective failure events occurring at varying pressure are presented in Table 1. The deflection at the cruciform increased from 1.78 to $14.34 \mathrm{~mm}$ while increasing the pressure from 10 to $50 \mathrm{kPa}$.

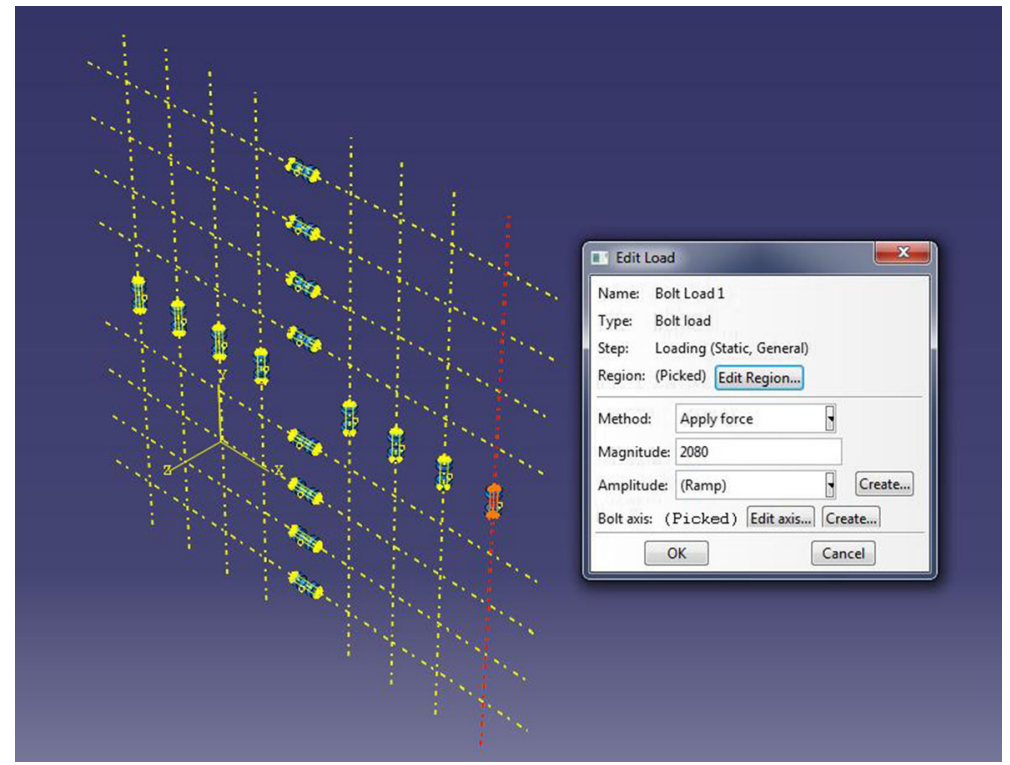

Fig. 5 Bolt preload 


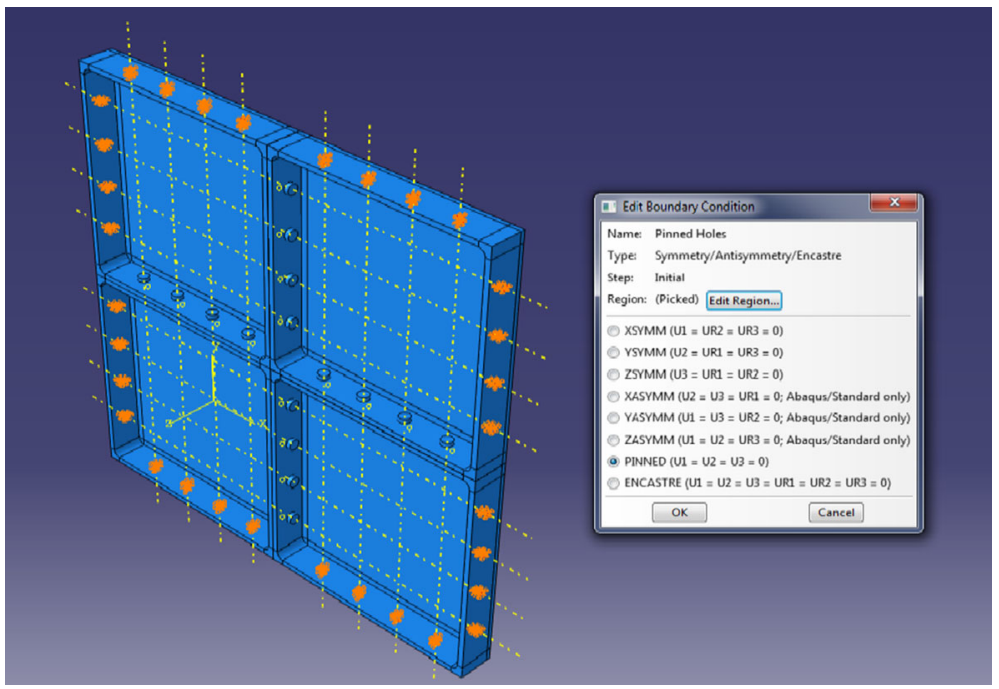

Fig. 6 Pinned boundary conditions applied to outer bolt holes

At a pressure of $35 \mathrm{kPa}$, cracking initiated at one of the panel corners and quickly spread to the flange face at the intersection of the panels (Fig. 3a). At $40 \mathrm{kPa}$, other panel corners cracked and spread to the flange faces at the four panel intersection. The cracks initiated at the end of the fillet radius in the corners (Fig. 3b). As the pressure was further increased, the corner cracks further propagated along the panel corners causing total rupture of the assembly at a pressure of $50 \mathrm{kPa}$ (Fig. 3c). We conclude that the safe maximum working pressure without cracking or rupture for the four panel bolted joint considered in this study is less than $35 \mathrm{kPa}$. Since the structure under consideration is a water storage tank, leak tightness is an important design factor to be taken into consideration. The structure attains ultimate failure state when matrix cracking initiates. Hence, the stress at which ultimate failure state occurs is the same as the stress at which matrix cracking starts. The damage process and the influence of bolt

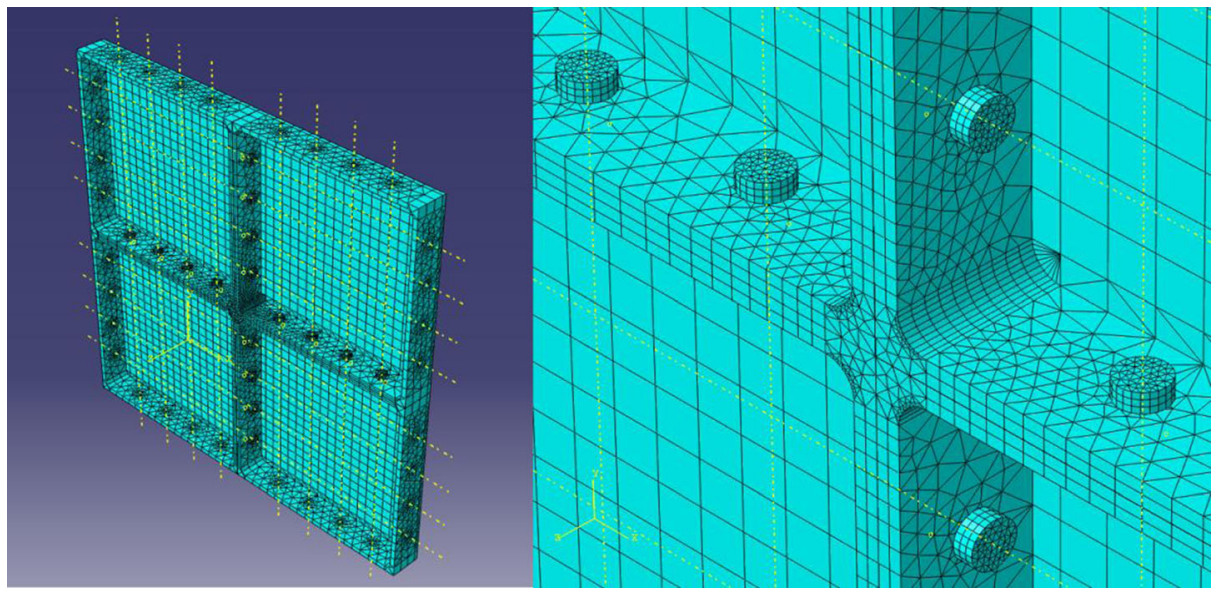

Fig. 7 Meshed FE model 
Table 2 Mechanical properties of materials in the panel assembly [27] [32]

\begin{tabular}{lllll}
\hline Material & Yield strength $(\mathrm{MPa})$ & Ultimate strength $(\mathrm{MPa})$ & Young's modulus $(\mathrm{GPa})$ & Poisson's ratio \\
\hline GRP & 100 & 100 & 12 & 0.3 \\
Steel & 450 & 700 & 200 & 0.3 \\
\hline
\end{tabular}

spacing and bolt pretension in improving the structural integrity of the joint was further investigated using finite element modelling.

\section{Finite Element Modelling}

\subsection{Model Setup}

Linear elastic finite element modelling was carried out using ABAQUS CAE software. The model comprised of two different parts - GRP panels and steel bolts. Dog-bone shaped bolts $12 \mathrm{~mm}$ in diameter were used in order to reduce the number of contact surfaces as shown in Fig. 4. These bolts simulate the effective force output by the washers on the GRP panel. Four GRP panels were bolted together similar to the assembly used in experimental testing. The bolt hole diameter and spacing are as considered in the experiment and stated earlier. Both GRP panels and steel bolts were modelled as three-dimensional, deformable solids.

To achieve faster convergence, the master surface was chosen as all the inner surfaces and shank of the bolts and the slave surface as the flange faces and bolt holes in the panels. Small sliding was chosen over finite sliding between surfaces as it typically results in more robust convergence behaviour which reduces computational time, despite finite sliding giving an arguably more accurate solution. A surface to surface discretization method was used as opposed to node to surface as it is generally accepted as a more accurate method. Under the slave adjustment tab, the 'adjust only to remove over closure' option was chosen again to allow for more robust convergence behaviour.

The interaction property 'Friction' was set up to model the frictional behaviour between the bolts and panels. Typical values of friction coefficient used in Finite Element Analyses vary between 0.2 and 0.33 for composite bolted joints [31]. Since the model consists of numerous contact surfaces, a constant value of 0.2 was used for all contacts in order to facilitate easy convergence. A low value of friction coefficient was used in order to minimize frictional losses

Fig. 8 Effect of pressure on the deflection of the four panel joint

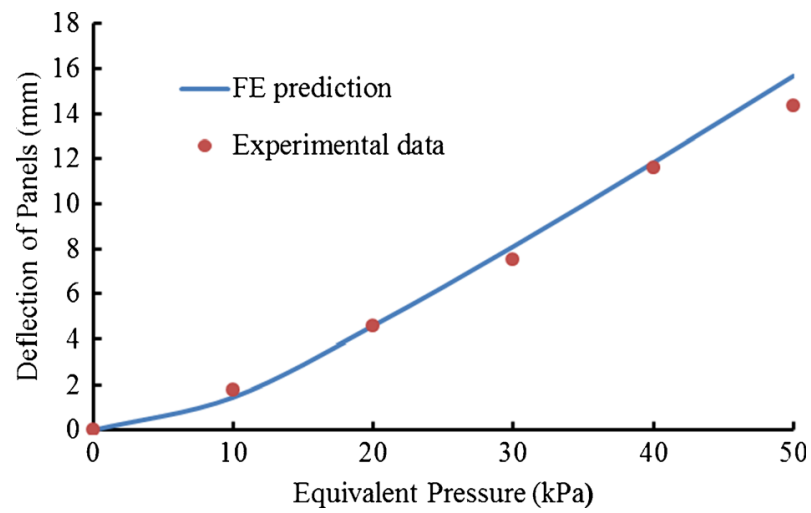




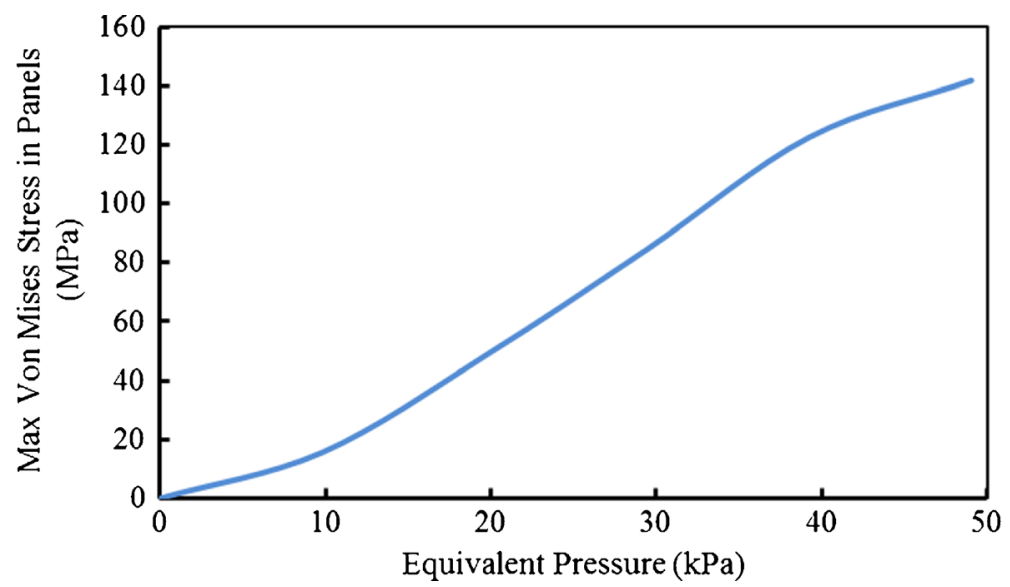

Fig. 9 Effect of pressure on maximum von Mises stress in side panels

between the bolt head and the panel thereby not leading to a reduction in clamping load. For normal behaviour, hard contact was selected and separation was allowed after contact. This selection also helps convergence behaviour during analysis whilst allowing an accurate representation of contact between bolt and panel. Similarly, contact was set up between each panel using the same method and friction interaction properties.

A constant magnitude of $2.08 \mathrm{kN}$ was selected for each bolt preload as shown in Fig. 5 . Varying equivalent pressure existing at different water depths ranging from 1 to $5 \mathrm{~m}$ was applied across the back face of the panels. Boundary conditions were set up so that the model was an accurate representation of a larger tank. Pinned supports were applied at all exterior bolt holes to simulate the effect of joining the assembly to the test fixture as shown in Fig. 6.

For the mesh, the panels were partitioned to separate the panel face from the flanges and then the flanges from the corner pieces. This allowed for structured meshing across the faces of the panels with sweep meshing around the bolt holes in the flanges. Wedge elements were used to mesh the complex circular edges in the model and hexagon elements to model the simple regions. Using wedge elements over the complex regions produced much more accurate

Fig. 10 Contours of von Mises equivalent stress at panel corner at the intersection of the four panels under a pressure of $40 \mathrm{kPa}$

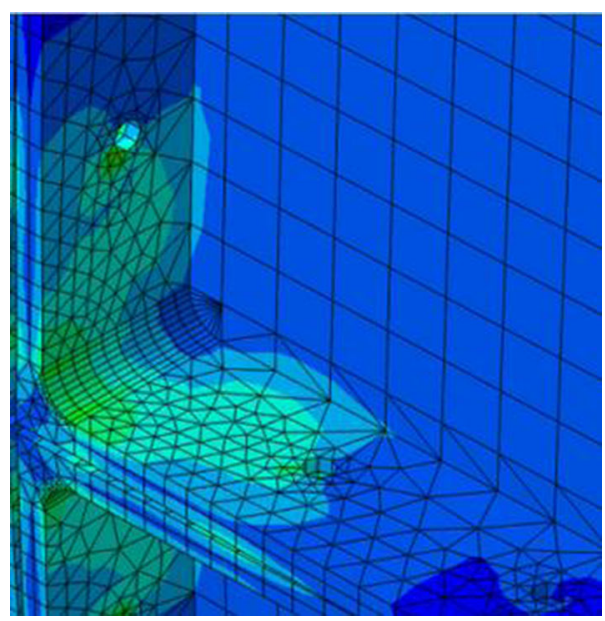




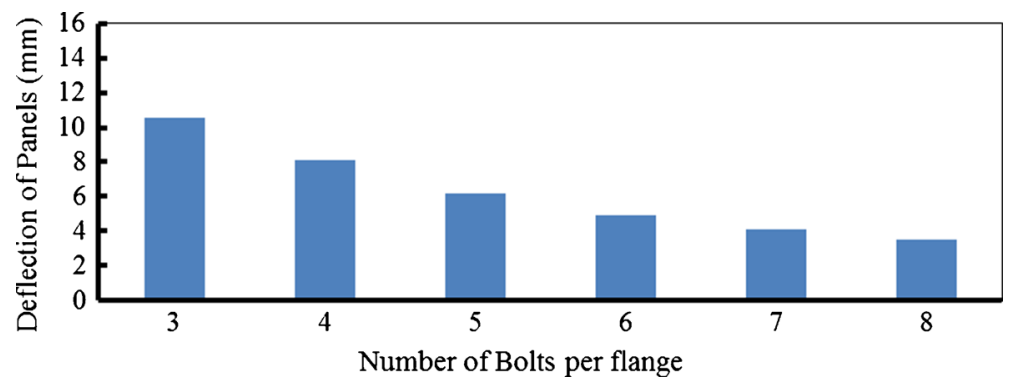

Fig. 11 Maximum displacement of the side panels versus number of bolts per flange at a pressure of $30 \mathrm{kPa}$

results than if using hexagon elements for all. Hence C3D6 elements - 6-node linear triangular prisms - were used to model the bolts and flanges and hexagon shaped C3D8R element - 8node linear bricks with reduced integration and hourglass control - were used to model the flat plates. The mesh was set up with an approximate global size of 25 seeds per GRP panel to give a relatively coarse mesh over the sections which experience less deformation. In areas of larger deformation and greater interest such as the interface of the 4 panels, a finer mesh was produced. The bolts were meshed with a fine approximate global size of 3.4 as they are a highly stressed and critical region. Along the top edges of the flanges, a seed bias of 5:1 with 25 elements per edge was used to give a denser distribution of seeds towards the panel interface. A greater number of seeds per edge were also applied to the 4 central corner pieces as this is the area where cracking initiates. A full view of the final mesh along with a zoomed in section of the centre is shown in Fig. 7.

The mechanical properties of the GRP panel and the steel bolts used in the analysis are given in Table 2. Uniform pressure was applied to the underside of the assembly as in the experiment.

\subsection{Effect of Varying Pressure}

The deflection at the intersection of the four panels increases with increasing pressure in a bilinear manner, see Fig. 8. The change in the global stiffness of the assembly occurs at a pressure of about $10 \mathrm{kPa}$ and deflection of $0.15 t$, where $t$ is the thickness of each panel. This change in stiffness could be associated with the transition from small deformation to finite deformation of the panels. The results from the simulation agree reasonably well with the experimental measurement (Fig. 8).

Fig. 12 Effect of number of bolts per flange on the maximum von Mises equivalent stress in the four panel bolted joint at a pressure of $30 \mathrm{kPa}$

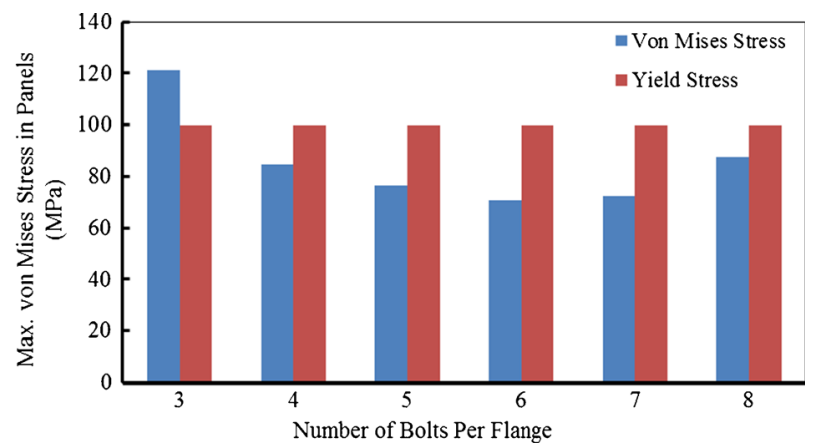




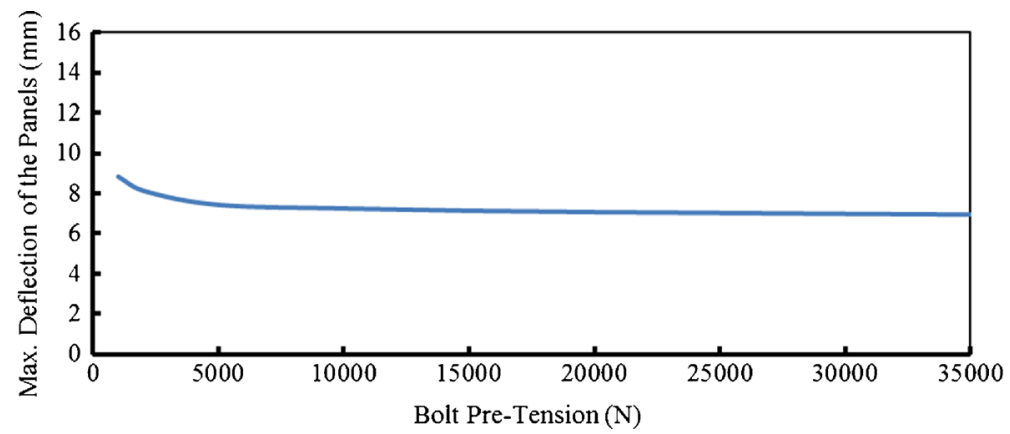

Fig. 13 The dependence of the maximum deflection of the four-panel bolted joint on the bolt pre-tension. The pressure load was $30 \mathrm{kPa}$

The maximum von Mises equivalent stress in the panels increases monotonically from 0 to 141.82 $\mathrm{MPa}$ as the applied pressure increases from 0 to $50 \mathrm{kPa}$ as shown in Fig. 9. We observed that the magnitude of the von Mises equivalent stress at the cruciform area exceeds the yield strength of the GRP $(100 \mathrm{MPa})$ at a pressure of $34 \mathrm{kPa}$. This is in good agreement with the results obtained in the rupture test because the panel corner cracked at a pressure of $35 \mathrm{kPa}$ in the rupture testing which confirms that GRP had exceeded the yield strength at that particular pressure. Since GRP is a brittle material, it does not lead to any plastic yielding but instead leads to crack initiation once the yield strength has been exceeded.

As pressure increases above $40 \mathrm{kPa}$, significant stresses build up at the intersection of the four panels and localised stress fields appear at the inner corners as shown in Fig. 10. This localised stress concentration causes cracking at the corners of the intersection and along the panel up to the first bolt hole as observed in the experiment. This high stress concentration is attributed to the excessive deflection of the cruciform area and the effect of varying bolt spacing and bolt pretension in decreasing this was investigated.

\subsection{Effect of Bolt Spacing}

Bolt spacing was varied by changing the number of bolts per flange whilst maintaining uniform spacing of bolts. The number of bolts (per flange) was varied from three bolts to a maximum of eight bolts. Models with one or two bolts per flange fall outside the maximum end distance as set out in British Standards BS 5959-1: 2000 [33] and hence were not considered. Similarly, models with nine or more bolts per flange approach the minimum bolt

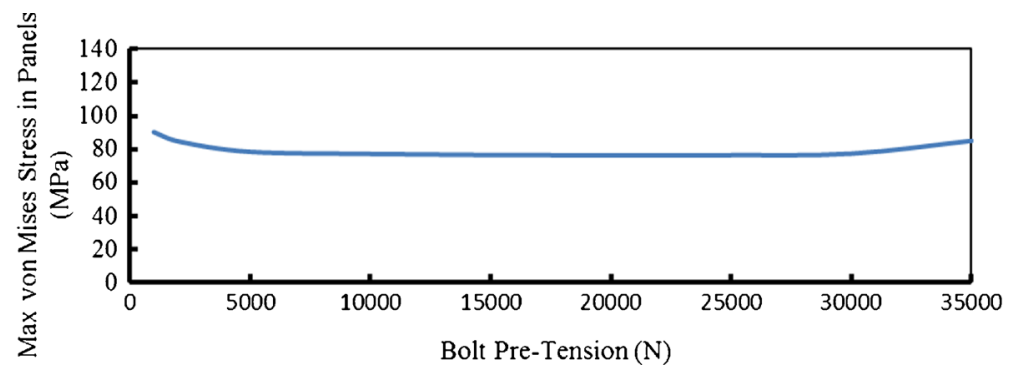

Fig. 14 Effect of bolt pre-tension on the maximum von Mises equivalent stress in the four-panel bolted joint at a pressure of $30 \mathrm{kPa}$ 
Table 3 Varying end distances and bolt spacing used in the investigation

\begin{tabular}{lll}
\hline$R$ & End distance $(\mathrm{mm})$ & Bolt spacing $(\mathrm{mm})$ \\
\hline $1: 1$ & 100.0 & 100.0 \\
$3: 4$ & 83.35 & 111.1 \\
$1: 2$ & 62.50 & 125.0 \\
$1: 3$ & 45.46 & 136.36 \\
$1: 4$ & 35.71 & 142.86 \\
\hline
\end{tabular}

spacing as stated in British Standards BS 5959-1: 2000 [33]. The panels were subjected to a maximum pressure of $30 \mathrm{kPa}$; this is slightly less than the $34 \mathrm{kPa}$ for which the von Mises equivalent stress was found to exceed the material yield stress when four bolts per flange were considered earlier and the bolt pretension used was $2.08 \mathrm{kN}$. Figure 11 shows the effect of varying bolt spacing on stress levels and deformation of the panels at the cruciform area.

We note that the maximum deflection decreased by almost $70 \%$ as the number of bolt per flange was increased from 3 to 8 . The von Mises equivalent stress in the cruciform area was also found to initially decrease with increasing number of bolts and subsequently increase with increasing number of bolts. The maximum equivalent stress decreased from $121.0 \mathrm{MPa}$ for 3 bolts per flange to $70.8 \mathrm{MPa}$ for 6 bolts per flange; a reduction of about $42 \%$ in the induced stress. The increase from 3 to 6 bolts per flange therefore gives a much better joint strength performance than for the GRP joint considered by Hart-Smith [8]. In the seven and eight bolts per flange models with a small end distance, maximum Von Mises stress increases slightly due to the close proximity of the outer external bolt holes to an area of large deformation in the panels. The equivalent stress increased from 70.8 to $87.6 \mathrm{MPa}$ when the number of bolts was increased from 6 to 8 bolts per flange, see Fig. 12. We conclude therefore that the in order to minimise the maximum stress in the assembly and therefore increase the load carrying capacity, the optimum number of bolts per flange is 6, for the material, panel dimensions and configuration under consideration.

\subsection{Effect of Bolt Pre-Tension}

The effect of bolt pretension was also studied by using varying bolt pretension value from 5 to $35 \mathrm{kN}$ in increments of $5 \mathrm{kN}$. These values were chosen as they are typical values for M12 steel bolts. The four panel bolted assembly with four bolts per flange was subjected to a pressure of $30 \mathrm{kPa}$. Figures 13 and 14 show the effect of bolt pre-tension on the deformation and stress levels respectively.

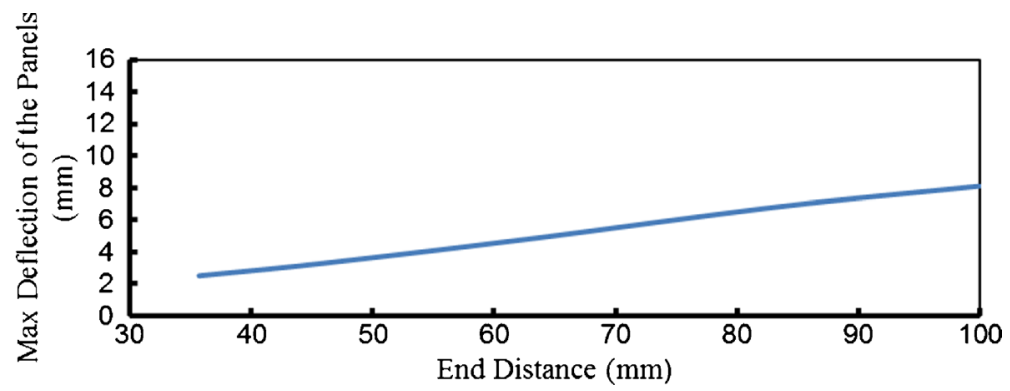

Fig. 15 Maximum deformation of the side panels versus end distance 


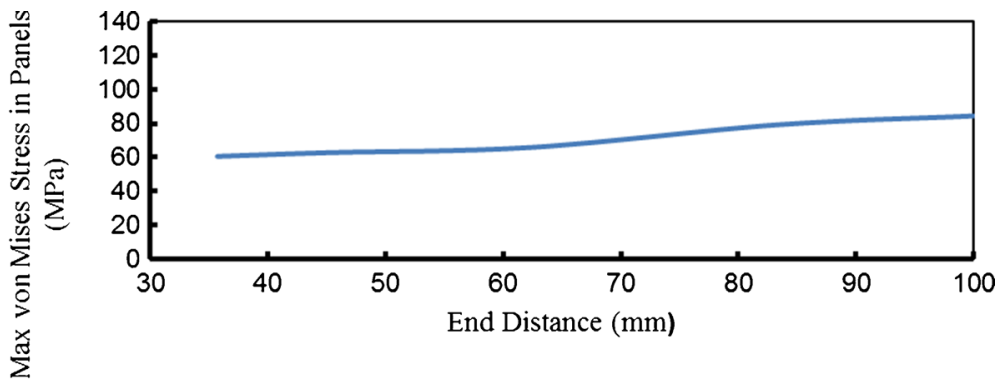

Fig. 16 Maximum von Mises stress in the side panels versus end distance

We note surprisingly that increasing the bolt pre-tension has an insignificant effect on the deflection and stress levels in the panels. This observation is in contrast to that by Stoekdale and Matthews [19] where increasing clamping load for GRP bolted joint was shown to improve joint performance; clamping load is directly related to the pre-tension. The friction coefficient used was 0.2 for all contact surfaces which is the lowest value in the range of $0.2-$ 0.33 for composite bolted joints [31]. Increasing bolt preload does not lead to significant increase in frictional forces due to the low coefficient of friction between the composite panels hence not significantly improving the slip resistance of the joints. This explains why there is no significant effect on the deflection and stress levels in the panels with increasing bolt preload $[34,35]$.

\subsection{Effect of Varying End Distances}

The end distance is defined as the distance from the outer most bolt hole to the nearest corner of the panel edge of the panel. Table 3 illustrates the dimensions of end distance and bolt spacing used in the investigation. The ratio of end distance to bolt spacing is taken as the ' $R$ ' value. While varying the edge distance, we maintained a constant number of four bolts per flange and a pre-tension of $2.08 \mathrm{kN}$. The applied pressure was $30 \mathrm{kPa}$.

As the end distance is reduced the displacement and the stress values decreases (Figs. 15 and 16). The further away the outermost bolts are from the edge of the bolted flange the more compliant the intersection of the panels is, leading to increased deflection and higher stress.

\section{Conclusions}

The present study helped to understand the failure process of a GRP flanged panel bolted joint subjected to varying surface pressures. It was found out that failure initiation started at the corners of the joints at the cruciform area. This could be attributed to the fact that maximum deflection occurred at the cruciform area which in turn leads to high localized stress concentration.

The experimental results of deflection and stresses at the cruciform area obtained showed good agreement with the FEA results. Experimental rupture testing showed that cracking initiated at $35 \mathrm{kPa}$ pressure and FEA results showed that the stresses in the panels exceeded the yield strength of the panels at the intersection of the four panels at a hydrostatic pressure of $34 \mathrm{kPa}$. The maximum safe working pressure to which GRP panel joint can be subjected without any risk of cracking was found to be $30 \mathrm{kPa}$. For the GRP panel joint configuration considered in this study subjected to a pressure of $30 \mathrm{kPa}$, we found that increasing the number 
of bolts and decreasing the end distance of the bolts from the corners had a considerable effect in reducing the deflection and stress concentration. However, increasing bolt pre-tension beyond a certain value did not have much of an impact in reducing the deflection of the joint. Taking into account, production and assembly efficiency, an end distance to bolt spacing ratio $\mathrm{R}$ of 1:2 with 5 bolts per flange with a bolt preload of $5 \mathrm{kN}$, were found to be the optimum joint parameters for the GRP panel joint under a pressure of $30 \mathrm{kPa}$.

Acknowledgments The authors acknowledge the financial support by the Technology Strategy Board; Balmoral Tanks Ltd., Llantrisant, Wales; and EPSRC through the Knowledge Transfer Partnership KTP 8649. The authors would like to thank the staff of Balmoral Tanks Ltd. for their support during the project, in particular Allan Joyce and Brian Bakewell for helpful discussion and Ceri Herbert for experimental assistance.

Open Access This article is distributed under the terms of the Creative Commons Attribution License which permits any use, distribution, and reproduction in any medium, provided the original author(s) and the source are credited.

\section{References}

1. Sundaram, S.: Oil-fuelling GRP growth in the Middle-East. Reinf. Plast. (2008). doi:10.1016/S00343617(08)70338-2

2. Devine, F.E., Jackson, J.R.: Cracking in bolted SMC components. Compos. Struct. 2(3), 223-234 (1984)

3. Godwin, E.W., Mathews, F.L., Kilty, P.F.: Strength of multi-bolt joints in GRP. Compos. 13(3), 268-272 (1982)

4. Rubben, A.: On the calculation of bolted joints for GRP plastics. Compos. Struct. 1(2), 175-187 (1983)

5. Bailie, J.A., Duggan, M.F., Bradshaw, N.C., McKenzie, T.G.: Design data for graphite cloth epoxy bolted joints at temperatures up to $450 \mathrm{~K}$. In: Kedward, K.T. (ed.) Joining of Composite Materials, pp. 165-180. ASTM, Baltimore (1981)

6. Madenci, E., Shkarayev, S., Sergeev, B., Oplinger, D.W., Shyprykevich, P.: Analysis of composite laminates with multiple fasteners. Int. J. Solids Struct. 35(15), 1793-1811 (1998)

7. Durante, M., Langella, A.: Bearing behavior of drilled and molded-in holes. Appl. Compos. Mater. 16, 297306 (2009)

8. Hart-Smith, L.J.: Mechanically fastened joints for advanced composites- phenomenological considerations and simple analyses. In: Lenoe, et al. (eds.) Fibrous Composites in Structural Design, pp. 543-574. Springer, New York (1980)

9. Bella, G.D., Calabrese, L.: Pin-contact behaviour of composite sandwich structures under compressive bearing load. Appl. Compos. Mater. 18, 197-210 (2011)

10. Ip, K.H., Chung K.F.: Failure modes of bolted cold-formed steel connections under static shear loading. In: Proceeding of the Second International Conference on Advances in Steel Structures, pp. 269-276. Hong Kong (1999)

11. Rhodes, J.: Design of cold-formed steel members. Elsevier, Essex (1991)

12. Chung, K.F.: Building Design Using Cold Formed Steel Sections Worked Examples to BS 5950: Part 5: 1987. The Steel Construction Institute, UK (1993)

13. Hancock, G.J.: Design of Cold-Formed Steel Structures. Australian Institute of Steel Construction, Australia (1998)

14. Yu, W.W.: Cold-Formed Steel Design. Wiley, New York (2000)

15. Oplinger, D.W.: On the behaviour of mechanically fastened joints in composite structures. In: Lenoe, et al. (eds.) Fibrous Composites in Structural Design, pp. 575-602. Springer, New York (1980)

16. Eissenman, J.R., Leonhardt, J.L.: Improving composite bolted joint efficiency by laminate tailoring. In: Kedward, K.T. (ed.) Joining of Composite Materials, pp. 117-130. ASTM, Baltimore (1981)

17. Agarwal, B.L.: Behaviour of Multifastener Bolted Joints in Composite Materials. 18th Aerospace Sciences Meeting. AIAA, Pasadena (1980)

18. Pyner, G.R., Mathews, F.L.: Comparison of single and multihole bolted joints in glass fibre reinforced plastic. J. Compos. Mater. 13(3), 232-239 (1979)

19. Stoekdale, J.H., Matthews, F.L.: The effect of clamping pressure on bolt bearing loads in glass fibre reinforced plastics. Compos. 7(1), 268-272 (1976) 
20. Collings, T.A.: The strength of bolted joints in multi-directional CFRP laminates. Royal Aircraft Establishment Technical Report 75127. Farnborough (1975)

21. Godwin, E.F., Mathews, F.L.: A review of the strength of joints in fibre-reinforced plastics: Part 1. Mechanically fastened joints. Composites 11(3), 155-160 (1980)

22. Hoa, S.V.: Analysis for Design of Fiber Reinforced Plastic Vessels and Piping. Technomic Publications, Lancaster (1991)

23. Estrada, H., Parsons, I.D.: Strength and leakage of finite element analysis of a GFRP flange joint. Int. J. Press. Vessel. Pip. 76(8), 543-550 (1999)

24. Blach, A.E., Hoa, S.V.: Bolted flange connections for glass fiber reinforced plastic pipes and pressure vessels. In: Proceedings of the 11th International Conference on Fluid Sealing, pp. 642-61. France (1987)

25. Sun, L.: Bolted flanged connections made of fiber reinforced plastic materials. PhD Dissertation. Concordia University, Montreal, Canada (1995)

26. Kia, H.G.: Sheet Molding Compounds: Science and Technology. Hanser/Gardner Publications, Inc., Cincinnati (1993)

27. British Standards Institution: BS EN 13280: 2001 Specification for Glass Fibre Reinforced Cisterns of OnePiece and Sectional Construction, for the Storage, Above Ground, of Cold Water. BSI, London (2001)

28. Menon, S.R., Guz, I., Akisanya, A.R., Kashtalyan, M., Wilkinson, C., Bakewell, B.: Optimisation of compression moulded SMC flanged panel joints under hydrostatic loading using finite element analysis and experimental testing. In: Proceedings of the International Conference on Deformation and Fracture of Composites \& Structural Integrity and Multi-Scale Modelling (DFC12/SI6), Cambridge (2013)

29. Oh, J.H., Kim, Y.G., Lee, D.G.: Optimum bolted joints for hybrid composite materials. Compos. Struct. 38(1-4), 329-341 (1997)

30. Tim, G.: Automotive service: Inspection, Maintenance, Repair (4th ed). Cengage Learning, Delmar (2012)

31. McCarthey, C.T., McCarthy, M.A., Stanley, W.F., Lawlor, V.P.: Experiences with modeling friction in composite bolted joints. J. Compos. Mater. 39(21), 188-28 (2005)

32. British Standards Institution: BS EN ISO 3506-1:2009 Mechanical Properties of Corrosion-Resistant Stainless Steel Fasteners. Bolts, Screws and Studs. BSI, London (2009)

33. British Standards Institution: BS 5959-1: 2000 Structural Use of Steelwork in Building. Code of Practice for Design, The Steel Construction Institute \& The British Constructional Steelwork Association Limited. BSI, London (2000)

34. Olmedo, A., Santiuste, C.: On the prediction of bolted single-lap composite joints. Compos. Struct. 94(6), 2110-2117 (2012)

35. Pearce, G.M., Johnson, A.F., Thomson, R.S., Kelly, D.W.: Experimental investigation of dynamically loaded bolted joints in carbon fibre composite structures. Appl. Compos. Mater. 17, 271-291 (2010) 